\title{
Treatment of spontaneous angina pectoris with beta blocking agents A clinical, electrocardiographic, and haemodynamic appraisal
}

\author{
Maurizio Guazzi, Cesare Fiorentini, Alvise Polese, Fabio Magrini, and Maria T. Olivari \\ From Istituto di Clinica Medica II, Istituto Ricerche Cardiovascolari, and Centro Ricerche Cardiovascolari del \\ Consiglio Nazionale delle Ricerche, University of Milan, Milan, Italy
}

\begin{abstract}
Propranolol and practolol were tested in patients with repeated daily occurrence of spontaneous angina. Twentyone showed ST segment depression (type I) and 15 ST segment elevation (type II) during angina. The efficacy of the treatment was evaluated in subjective (number of reported episodes of pain) and ctjective terms (number of episodes of electrocardiographic abnormalities documented during periods of continuous recording): practolol was fully effective in 42 per cent and propranolol in 38 per cent of type I cases; in type II angina 73 per cent of the cases fully responded to propranolol, none of the patients in this group given practolol improved.

The study also showed that: (a) the effects on angina are strictly dose-dependent, and optimal results are achieved at individualized doses; (b) within the same subject the response may be preferential to one betablocker as opposed to the other; (c) propranolol is more effective in type II angina; (d) the occurrence of heart failure is uncommon even with high doses of beta blockers; (e) the relief of angina is due to prevention of ischaemia and not to a placebo or anaesthetic effect; (f) the prevention of ischaemia is not adequately explained by reduction of the mechanical effort and the oxygen need of the myocardium; (g) the antianginal effect is possibly dissociated from the beta blockade of the heart.
\end{abstract}

The hypothesis that beta-blocking agents influence the coronary vasomotion is discussed.

The basis for the treatment of angina pectoris by heta blockers may be viewed in terms of the pathophysiology of angina and its relation to cardiac adrenergic stimulation. Angina pectoris is thought to be the result of an imbalance between myocardial oxygen demand and supply (Gorlin, 1965). Beta blockade is directed at the prevention of myocardial ischaemia and resultant pain by restricting cardiac contractile effort. This is achieved through pharmacological blockade of the myocardial betaadrenergic receptors, thereby attenuating the increase in myocardial oxygen requirement which accompanies adrenergic stimulation, namely, during emotional stress or physical exercise.

Chest pains coming on at rest, not related to deliberate laboratory stress or any other detectable eliciting factor, accompanied by unequivocal electrocardiographic alterations are defined as 'spontaneous' angina. The electrocardiographic Received 18 April 1975. changes in spontaneous angina may present in two different forms: ( $a$ ) ischaemic ST segment depression in the leads reflecting left ventricular epicardial potentials (which we call angina type I); (b) ST elevation in some leads with reciprocal depression in the opposite leads, which is characteristic of the variant form of angina pectoris described by Prinzmetal et al. (1959) (angina type II). Haemodynamic monitoring during continuous electrocardiographic recording has shown that neither type of electrocardiographic change is preceded by variations of heart rate, arterial pressure, cardiac output, or duration of right and left ventricular contraction (Guazzi et al., 1971b; 1975). Consequently, these episodes of acute myocardial ischaemia are not attributable to changes in the work of the heart and its oxygen needs. Spontaneous angina, therefore, cannot be interpreted on the basis of the classical pathophysiology. In particular, an increased contractile effort consequent on catechol- 
amine stimulation can be excluded as the trigger mechanism of the ischaemia. For these reasons the effect of beta blockers in spontaneous angina appeared worthy of investigation.

This is an expansion of earlier work on Prinzmetal's (type II) angina (Guazzi et al., 1971a); it also presents our experience with a large population of patients suffering from type I angina. The results of the study are reported both for their practical importance, especially if confirmed by others, and for their theoretical interest in relation to the pathogenesis of spontaneous angina, the mechanism of the antianginal action of beta receptors' antagonists, and their effects on the circulatory function of patients suffering from spontaneous angina. To assess the relative importance of local anaesthetic effect and betaadrenergic antagonism in the treatment of these patients, propranolol, which has cell membrane activity, was tested as well as practolol, which has not (Fitzgerald, 1969).

\section{Subjects and Methods}

\section{Subjects}

Patients were selected for the study who on admission had a daily occurrence of at least three episodes of chest pain at rest, of typical quality and location. The history of angina in these patients varied from four months to three years. Cases in which there was a sudden increase in severity and frequency of angina were excluded. Patients with a history or evidence of heart failure, arterial hypertension, or valvular or pulmonary diseases were also excluded from the study. The purpose and the nature of the investigative programme, the possible clinical benefits, and the scientific aspects of the study were explained in detail to each patient; without inducement all willingly consented to participation in the study. Twenty-one patients with type I angina were investigated. The basal electrocardiogram was normal in 10 cases, in 7 it showed old myocardial infarction, and in 8 it showed flat or negative $T$ waves in the lateral praecordial leads. In each case angina was accompanied by $T$ wave inversion and ST segment depression in the leads reflecting left ventricular epicardial potentials. Fifteen patients with type II angina entered the study. The baseline electrocardiogram was normal in 7 , it showed old infarction in 5, and negative $T$ waves in the inferior leads in 3. Seven of these patients during angina showed ST segment elevation in the anterior and 8 in the inferior leads, with reciprocal depression in the opposite leads.

\section{Plan of investigation}

It was felt that more convincing evidence of the efficacy of the treatment could be provided through the evaluation not simply of the subjective response (number of episodes of pain reported) but also of the objective effects (number of episodes of electrocardiographic changes of ischaemia documented during continuous recording). Accordingly the investigation was designed as follows: (a) daily charting in a diary throughout the runin and trial of the number, time, and circumstances of the anginal attacks in the 24 hours. (b) Administration during the run-in (first week of hospitalization) of placebo tablets identical in colour, shape, and taste to the active drug to be given, with allowance of nitroglycerin consumption. (c) Continuous electrocardiographic recording during 7 to 8 hours after the run-in period (the hours during which this was carried out were selected as indicated below). (d) Haemodynamic evaluation the day after the continuous recording of the electrocardiogram. (e) Oral administration of propranolol or practolol continued for several days, the choice of the drug to start with being made randomly. $(f)$ Repeat of the electrocardiographic monitoring after a full subjective effect was obtained (full effect was considered to be achieved only after the patients had remained free of pain for at least one week), or after the discontinuance of the drug was decided (the criteria for discontinuance are noted below). $(g)$ Replacement of the discontinued drug with the other. ( $h$ ) Repeat of the electrocardiogram continuous recording after a full subjective response to the new drug was obtained or after the maximal arbitrary dosage was reached. (i) Replacement, in the responding subjects, of the active drug by placebo tablets in equal number. $(j)$ Re-establishment of the active treatment, and discharge on the same doses of the drug which had induced optimal therapeutic effect. The haemodynamic evaluations were repeated during the periods $f$ and $h$.

Daily charting of the anginal episodes was valuable both for estimating the subjective response to treatment and for indicating during which hours of the day angina occurred most often for each patient in the pretreatment state. The electrocardiographic tests were repeated during these same hours during the periods $c, f$, and $h$, and consisted of a 7 to 8 hour recording of the four leads which presented the most evident alterations of ischaemia. In every case these alterations were so clear that they could be consistently detected even at a recording speed as low as $0.5 \mathrm{~mm} / \mathrm{s}$.

Propranolol was distributed in four equal doses in the 24 hours, the dosage starting at $80 \mathrm{mg}$ daily which, according to the patient's response, was subsequently increased by $80 \mathrm{mg}$ every other day, with an arbitrary upper limit of $800 \mathrm{mg}$ daily. The increment was interrupted at any lower dosage which induced a full antianginal effect. The drug was discontinued when half the maximal dose had been reached without any tendency of angina to decrease being observed, or at any amount which induced adverse side effects (primarily, excessive bradycardia or clinical signs of cardiac insufficiency). Practolol was started at $200 \mathrm{mg}$ daily, and increased by $200 \mathrm{mg}$ every other day in accordance with the same criteria as for propranolol; the arbitrary upper limit was $500 \mathrm{mg}$ four times a day.

\section{Pharmacological tests}

The fact that in several cases in both groups the angina improved better on one rather than the other of the 
two beta blockers could have been attributable to a different degree of cardiac beta blockade induced by one drug as compared with the other in that particular patient. A quantification of the beta-adrenergic blockade of the heart seemed likely to prove or disprove this interpretation. Consequently changes induced in the resting heart rate by scalar doses $(0.5,1,2,5 \mu \mathrm{g} / \mathrm{min}$ over 5 minutes) of isoprenaline administered intravenously through a continuous infusion pump were tested before treatment and at each increasing amounts of the two drugs. We considered that an increase in rate of 30 beats/min or an absolute tachycardia of 110 beats/ min in the control phase was a satisfactory and safe end-point for the test. Such response was generally elicited by an isoprenaline dose of $5 \mu \mathrm{g} / \mathrm{min}$. Beat-tobeat variations of pulse rate were detected through a cardiotachograph. The isoprenaline effect was tested 6 hours after the previous dose of the beta-receptor antagonist.

\section{Haemodynamic methods}

The cardiovascular function of these patients was assessed by the following measurements: heart rate (HR); arterial pressure (AP); mean right atrial pressure (MRAP); cardiac index (CI); tension-time index per minute (TTI); left ventricular work (LVW); left ventricular mean rate of systolic ejection (MSEJR); left ventricular mean isometric contraction (dP/dt). In type I angina group measurements were performed in the control state in nine subjects; five of them were reinvestigated while on propranolol and seven while on practolol; in three cases the study was repeated during both periods of treatment. Twelve type II anginal patients were investigated in the untreated state and while on propranolol; in three of these the haemodynamic evaluation was also repeated during practolol.

Studies were carried out three hours after the last dose of beta blocker in the steady state, without premedication, in the supine position. Steady state was considered to be achieved when heart rate and arterial pressure had stabilized. In any case, the measurements were not begun until at least 30 minutes after completing the catheter introductions. For the measurement of right atrial pressure a polyethylene catheter was inserted into an antecubital vein and positioned in the right atrium. An 18-gauge Teflon catheter needle, introduced into the brachial artery, was used to sample indocyanine green for cardiac output and to monitor arterial pressure. Dye dilution analyses of cardiac output were performed after injection of indocyanine green $(5 \mathrm{mg})$ into the right atrium and withdrawal from the brachial artery.

Cardiac index, stroke index, and mean systolic ejection rate were calculated in the standard fashion. Measurements of the pre-ejection period and left ventricular ejection time were obtained from the simultaneous recording, at a paper speed of $100 \mathrm{~mm} / \mathrm{s}$, of the electrocardiogram, carotid sphygmogram and phonocardiogram, according to the method reported by Weissler, Harris, and Schoenfeld (1968). The left ventricular mean $\mathrm{dP} / \mathrm{dt}$ was derived by dividing the diastolic arterial pressure by the simultaneous values of the pre-ejection per:od. Tension-time index per minute was obtained as the product of mean systolic arterial pressure, left ventricular ejection time, and heart rate; left ventricular minute work was calculated from the following formula:

$\mathrm{LVW}\left(\mathrm{kg} \cdot \mathrm{m}\right.$ per $\mathrm{m}^{2}$ bsa $)=\frac{\mathrm{MSAP} \times \mathrm{SI} \times \mathrm{HR} \times 0.136}{1000}$,

where MSAP = mean systolic arterial pressure in $\mathrm{mmHg} ; \mathrm{SI}=$ stroke index in $\mathrm{ml}$ per $\mathrm{m}^{2}$ bsa; $\mathrm{HR}=$ heart rate.

\section{Results}

Clinical and electrocardiographic effects

In patients of both groups no antianginal effect was observed while on placebo during the run-in period.

Table 1 shows the incidence of pain in the 24 hours for the type I angina group, and the number of episodes of electrocardiographic alteration documented during continuous electrocardiographic recordings, in the untreated state, after propranolol and after practolol. The maximal dosage administered and the sequence in which the two drugs were given are also indicated. In Cases 2,6 , and 18 episodes of ST segment depression were recorded which were unaccompanied by pain; the figures in parentheses indicate these episodes. Twelve patients (Cases 1 to 12) received propranolol first, which induced a full antianginal effect in four (Cases 1 to 4); in Cases 5 to 10 the drug was discontinued at doses noted in the Table, and replaced with practolol. The reasons were: excessive bradycardia (Cases 6 and 8); some degree of nocturnal dyspnoea (Cases 5 and 9); no tendency of angina to decrease despite progressive increase of dosage (Cases 7 and 10). In each of these cases practolol induced full relief of angina without any noticeable adverse side effect. Case 12 died from cardiac arrest during angina while treated with a daily amount of $160 \mathrm{mg}$ propranolol, which was ineffective in reducing the number of pain reports. It is noteworthy that in many of the patients an antianginal response was obtained at doses of practolol relatively equal to or lower than those doses of propranolol which had been ineffective.

Nine patients received practolol first, which was fully effective in three cases $(13,14,15)$; in six (Cases 16 to 21) angina did not show any tendency to decrease. Propranolol was then administered, and doses could be reached which were fully effective in Cases 16, 17, and 18 and partially effective in Cases 19 and 20 . In Case 19 bradycardia prevented the administration of the upper arbitrary dose. In Cases 16 and 21 propranolol abolished angina at doses proportionally lower than those of practolol, which had been ineffective. 
TABLE 1 Number of reports of pain in the 24 hours, and nu nber of episodes of electrocardiographic alterations of ischaemia in the untreated state, after propranolol and after practolol in the group of patients suffering from type I angina pectoris.

\begin{tabular}{|c|c|c|c|c|c|c|c|c|}
\hline \multirow[b]{2}{*}{$\begin{array}{l}\text { Case } \\
\text { No. }\end{array}$} & \multicolumn{2}{|l|}{ Control } & \multicolumn{3}{|c|}{ Propranolol } & \multicolumn{3}{|c|}{ Practolol } \\
\hline & $\begin{array}{l}\text { Reports of pain } \\
24 \mathrm{hr}\end{array}$ & $\begin{array}{l}E C G \\
\text { study }\end{array}$ & $\begin{array}{l}\text { Dose } \\
\text { mg/day }\end{array}$ & $\begin{array}{l}\text { Reports of pain } \\
24 \mathrm{hr}\end{array}$ & $\begin{array}{l}E C G \\
\text { study }\end{array}$ & $\begin{array}{l}\text { Dose } \\
\text { mg/day }\end{array}$ & $\begin{array}{l}\text { Reports of pain } \\
24 \mathrm{hr}\end{array}$ & $\begin{array}{l}\text { ECG } \\
\text { study }\end{array}$ \\
\hline $\begin{array}{r}1 \\
2 \\
3 \\
4 \\
5 \\
6 \\
7 \\
8 \\
9 \\
10 \\
11 \\
12\end{array}$ & $\begin{array}{c}6-8 \\
9-10 \\
2-4 \\
4-5 \\
3-4 \\
3-5 \\
8-10 \\
3-4 \\
3-4 \\
4-5 \\
10-13 \\
6-7\end{array}$ & $\begin{array}{l}2 \\
4(4) \\
1 \\
2 \\
2 \\
2(2) \\
3 \\
1 \\
1 \\
1 \\
4 \\
3\end{array}$ & $\begin{array}{l}240 \\
480 \\
160 \\
160 \\
240 \\
160 \\
400 \\
240 \\
160 \\
400 \\
320 \\
160\end{array}$ & $\begin{array}{l}\text { None } \\
\text { None } \\
\text { None } \\
\text { None } \\
2-4 \\
3-5 \\
8-15 \\
2-3 \\
3-4 \\
4-5 \\
1-2 \\
-\end{array}$ & $\begin{array}{l}\text { None } \\
\text { None } \\
\text { None } \\
\text { None } \\
2 \\
2(1) \\
2 \\
1 \\
\text { None } \\
2 \\
1 \\
-\end{array}$ & $\begin{array}{l}- \\
- \\
\overline{6} \\
600 \\
800 \\
600 \\
600 \\
400 \\
600 \\
-\end{array}$ & $\begin{array}{l}- \\
- \\
\overline{-} \\
\text { None } \\
\text { None } \\
\text { None } \\
\text { None } \\
\text { None } \\
\text { None } \\
- \\
-\end{array}$ & $\begin{array}{l}- \\
- \\
- \\
\text { None } \\
\text { None } \\
\text { None } \\
\text { None } \\
\text { None } \\
\text { None } \\
- \\
-\end{array}$ \\
\hline 12 & \multicolumn{2}{|l|}{ Control } & \multicolumn{3}{|c|}{ Practolol } & \multicolumn{3}{|c|}{ Propranolol } \\
\hline $\begin{array}{l}13 \\
14 \\
15 \\
16 \\
17 \\
18 \\
19 \\
20 \\
21\end{array}$ & $\begin{array}{c}4-5 \\
2-3 \\
1-4 \\
3-4 \\
3-5 \\
15-22 \\
4-6 \\
6-8 \\
4-5\end{array}$ & $\begin{array}{l}1 \\
1 \\
1 \\
1 \\
2 \\
6(3) \\
2 \\
2 \\
3\end{array}$ & $\begin{array}{r}2000 \\
800 \\
600 \\
1000 \\
1000 \\
1000 \\
1000 \\
1200 \\
1000\end{array}$ & $\begin{array}{c}\text { None } \\
\text { None } \\
\text { None } \\
4-5 \\
4-5 \\
16-20 \\
3-6 \\
5-8 \\
5-6\end{array}$ & $\begin{array}{l}\text { None } \\
\text { None } \\
\text { None } \\
2 \\
1 \\
7(2) \\
2 \\
3 \\
2\end{array}$ & $\begin{array}{l}- \\
- \\
240 \\
480 \\
400 \\
480 \\
800 \\
320\end{array}$ & $\begin{array}{l}- \\
- \\
\bar{N} \text { None } \\
\text { None } \\
\text { None } \\
1-3 \\
1-3 \\
\text { None }\end{array}$ & $\begin{array}{l}- \\
- \\
\text { None } \\
\text { None } \\
\text { None } \\
1 \\
1 \\
\text { None }\end{array}$ \\
\hline
\end{tabular}

Figures in parentheses are additional and indicate the episodes of ischaemia recorded in the absence of pain.

TABLE 2 Number of reports of pain in the 24 hours, and number of episodes of electrocardiographic abnormalities of ischaemia in the group of patients suffering from type II angina pectoris.

\begin{tabular}{|c|c|c|c|c|c|c|c|c|}
\hline \multirow[b]{2}{*}{$\begin{array}{l}\text { Case } \\
\text { No. }\end{array}$} & \multicolumn{2}{|l|}{ Control } & \multicolumn{3}{|c|}{ Propranolol } & \multicolumn{3}{|c|}{ Practolol } \\
\hline & $\begin{array}{l}\text { Reports of pain } \\
24 \mathrm{hr}\end{array}$ & $\begin{array}{l}\text { ECG } \\
\text { study }\end{array}$ & $\begin{array}{l}\text { Dose } \\
\text { mg/day }\end{array}$ & $\begin{array}{l}\text { Reports of pain } \\
24 \mathrm{hr}\end{array}$ & $\begin{array}{l}E C G \\
\text { study }\end{array}$ & $\begin{array}{l}\text { Dose } \\
\text { mg/day }\end{array}$ & $\begin{array}{l}\text { Reports of pain } \\
24 \mathrm{hr}\end{array}$ & $\begin{array}{l}\text { ECG } \\
\text { study }\end{array}$ \\
\hline $\begin{array}{l}1 \\
2 \\
3 \\
4 \\
5 \\
6 \\
7 \\
8 \\
9\end{array}$ & $\begin{array}{c}8-12 \\
5-6 \\
2-3 \\
10-12 \\
4-7 \\
4-5 \\
8-12 \\
8-10 \\
0\end{array}$ & $\begin{array}{l}6(7) \\
8(7) \\
3(3) \\
3(4) \\
3 \\
2 \\
3(1) \\
6 \\
0(10)\end{array}$ & $\begin{array}{l}240 \\
480 \\
160 \\
240 \\
400 \\
240 \\
160 \\
800 \\
800\end{array}$ & $\begin{array}{l}\text { None } \\
\text { None } \\
\text { None } \\
\text { None } \\
\text { None } \\
\text { None } \\
1-2 \\
\text { None } \\
0\end{array}$ & $\begin{array}{l}\text { None } \\
\text { None } \\
\text { None } \\
\text { None } \\
\text { None } \\
\text { None } \\
\text { None } \\
\text { None } \\
\text { None }\end{array}$ & $\begin{array}{l}- \\
- \\
- \\
- \\
- \\
-\end{array}$ & $\begin{array}{l}- \\
- \\
- \\
- \\
- \\
-\end{array}$ & $\begin{array}{l}- \\
z \\
z \\
z \\
z\end{array}$ \\
\hline 9 & \multicolumn{2}{|l|}{ Control } & \multicolumn{3}{|c|}{ Practolol } & \multicolumn{3}{|c|}{ Propranolol } \\
\hline $\begin{array}{l}10 \\
11 \\
12 \\
13 \\
14 \\
15\end{array}$ & $\begin{array}{c}4-10 \\
3-5 \\
10-15 \\
4-6 \\
8-10 \\
3-4\end{array}$ & $\begin{array}{l}2 \\
2 \\
6(4) \\
1 \\
4 \\
2\end{array}$ & $\begin{array}{l}1000 \\
1200 \\
1600 \\
1000 \\
1000 \\
1200\end{array}$ & $\begin{array}{c}8-10 \\
3-4 \\
10-12 \\
3-5 \\
8-10 \\
3-5\end{array}$ & $\begin{array}{l}2 \\
1 \\
6(3) \\
1 \\
5 \\
3\end{array}$ & $\begin{array}{l}240 \\
320 \\
640 \\
400 \\
600 \\
640\end{array}$ & $\begin{array}{l}\text { None } \\
\text { None } \\
\text { None } \\
1-2 \\
6-9 \\
3-5\end{array}$ & $\begin{array}{l}\text { None } \\
\text { None } \\
\text { None } \\
\text { None } \\
2 \\
2\end{array}$ \\
\hline
\end{tabular}

Figures in parentheses are additional and indicate the episodes of ischaemia recorded in the absence of pain. 
In summary, 80 per cent of the patients in type I group had total abolition of the anginal symptoms by beta blockers; in 38 per cent of the cases the optimal effect was obtained with propranolol, in 42 per cent with practolol.

In the responder subjects it was found that: treatment did not significantly influence the baseline electrocardiogram; the antianginal effect was dosedependent; and the phasic electrocardiographic changes of myocardial ischaemia were abolished in parallel with the relief of the subjective symptoms. In this connexion the disappearance also of the ST segment changes which were not accompanied by pain was of particular interest.

After replacement of the active drug by placebo each of these patients complained again of angina within 2 to 3 days.

Table 2 summarizes the findings in the type II angina group. Propranolol was given in nine cases (1 to 9): angina was completely relieved in eight of them and reduced in one (Case 7). In Cases 10 to 15 practolol was unsuccessful; in the same cases propranolol gave the following results: no effect in two (Cases 14 and 15), partial relief of angina in one (Case 13), and complete relief in three (Cases 10 to 12). In these last patients propranolol was effective at doses proportionally lower than those of practolol, which had been ineffective. As for type I angina it was found in the responder patients that: treatment did not change the baseline electrocardiogram; the antianginal response was doserelated; improvement was subjective and objective; and treatment was effective on both the painful and painless electrocardiographic changes caused by ischaemia. The success of propranolol is remarkable in Case 9, in whom none of the recorded episodes of ST segment elevation was accompanied by pain.

In summary, in type II angina administration of beta blockers was fully effective in 73 per cent of the cases; none of the patients in this group who were given practolol improved; propranolol succeeded in 66 per cent of the cases in which practolol had failed. In each of the responder subjects angina reappeared after replacement of the active drug with placebo.

\section{Isoproterenol infusion}

The average increments of the resting pulse rate induced by isoprenaline in the untreated state were as follows: 9 per cent at $0.5 \mu \mathrm{g} / \mathrm{min}, 17$ per cent at $1 \mu \mathrm{g} / \mathrm{min}, 33 \mathrm{per}$ cent at $2 \mu \mathrm{g} / \mathrm{min}$, and 37 per cent at $5 \mu \mathrm{g} / \mathrm{min}$. While propranolol and practolol showed (Tables 1 and 2) great differences in the same patient as far as the effect on angina is concerned, equivalent doses of the two drugs showed comparable blocking properties on the isoprenalineinduced tachycardia. In each case the response rate progressively fell in parallel with the increasing amount of the beta blocker, and it fully disappeared at the average daily doses of $192 \mathrm{mg}$ propranolol and $533 \mathrm{mg}$ practolol. These figures were both significantly lower $(P<0.01)$ than those required to achieve a complete antianginal effect, the average effective antianginal doses of propranolol and practolol being, respectively, 368 and $688 \mathrm{mg}$ a day. In Fig. 1 (Case 11 in Table 2) a graphic presentation is given of the relation between increasing amounts of practolol and propranolol, blockade of the isoprenaline-induced tachycardia, and antianginal effect. Though practolol and propranolol had shown similar degrees of blockade of the response to isoprenaline, only propranolol relieved the anginal symptoms.

In no case in this study did isoprenaline infusion precipitate angina.

\section{Haemodynamic effects}

Our previous studies (Guazzi et al., 1971a, b; 1975) showed that in both types of angina the electrocardiographic abnormalities of ischaemia are not preceded, and consequently not attributable to, variations from the baseline of the circulatory functions which determine the haemodynamic load of the heart and its oxygen needs. The favourable effects of the beta blockers, therefore, are not to be interpreted as a prevention or a restriction of a sudden increase in the mechanical effort of the heart, which indeed is not responsible for eliciting spontaneous attacks of angina. In the present study the hypothesis was considered that variations in the baseline haemodynamic load on the left ventricle after treatment might be somehow related to the improvement of the anginal symptoms. In Fig. 2 (type I angina) and Fig. 3 (type II angina) changes from the control state (C) induced by practolol $(\mathrm{Pc})$ and propranolol $(\mathrm{Pr})$ on the basal values of left ventricular work (LVW) and tensiontime index (TTI) are related to the antianginal response. The values corresponding to full relief of angina are indicated by open squares. It is evident that in both types of angina no consistent relation exists between variations of LVW and TTI from the control state and relief of angina; actually, this occurred at levels of LVW and TTI either higher or lower than in the untreated condition. It is also remarkable that one of the two beta blockers was successful in some cases in which the other had failed, though the levels of left ventricular load were higher after the former and lower after the latter drug as compared to the pretreatment state. 
1240 Guazzi, Fiorentini, Polese, Magrini, and Olivari

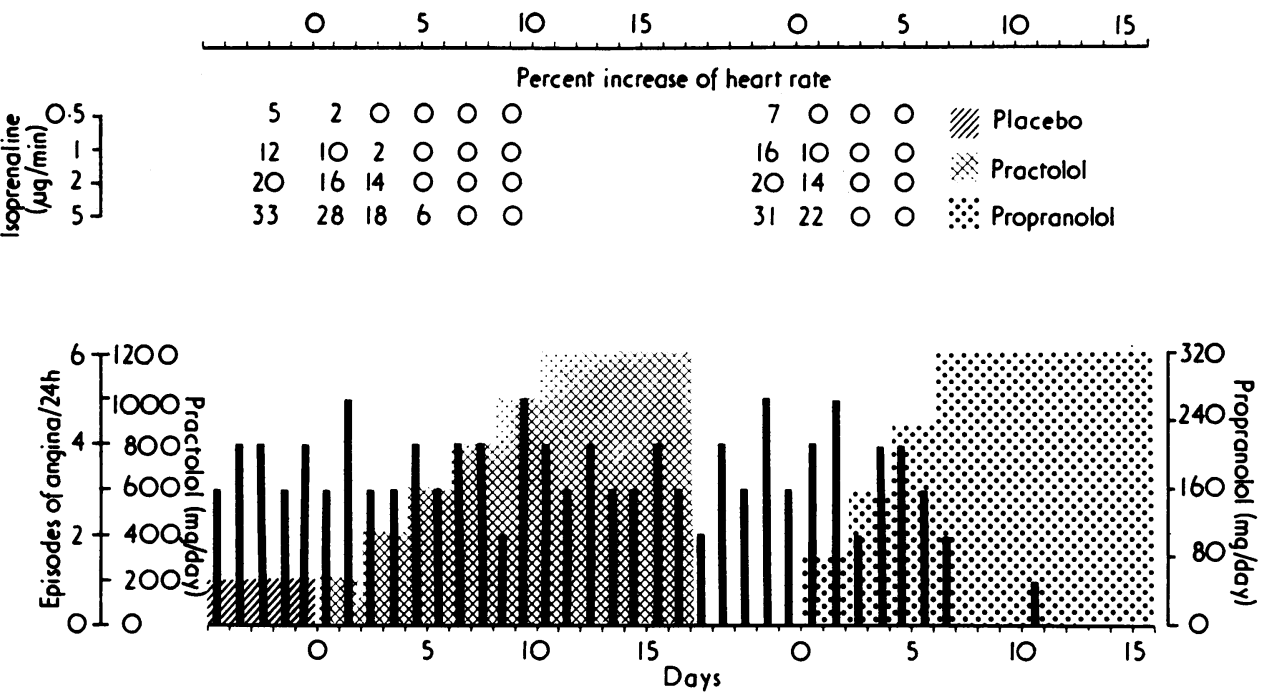

FIG. 1 Relation between increasing amounts of practolol and propranolol; blockade of the isoprenaline-induced tachycardia and antianginal response in a patient suffering from type II angina pectoris. The number of episodes of chest pains in the 24 hours is indicated by vertical bars. Though equivalent doses of the two drugs induce comparable degree of blockade of the rate response to isoprenaline, only propranolol is effective on angina.
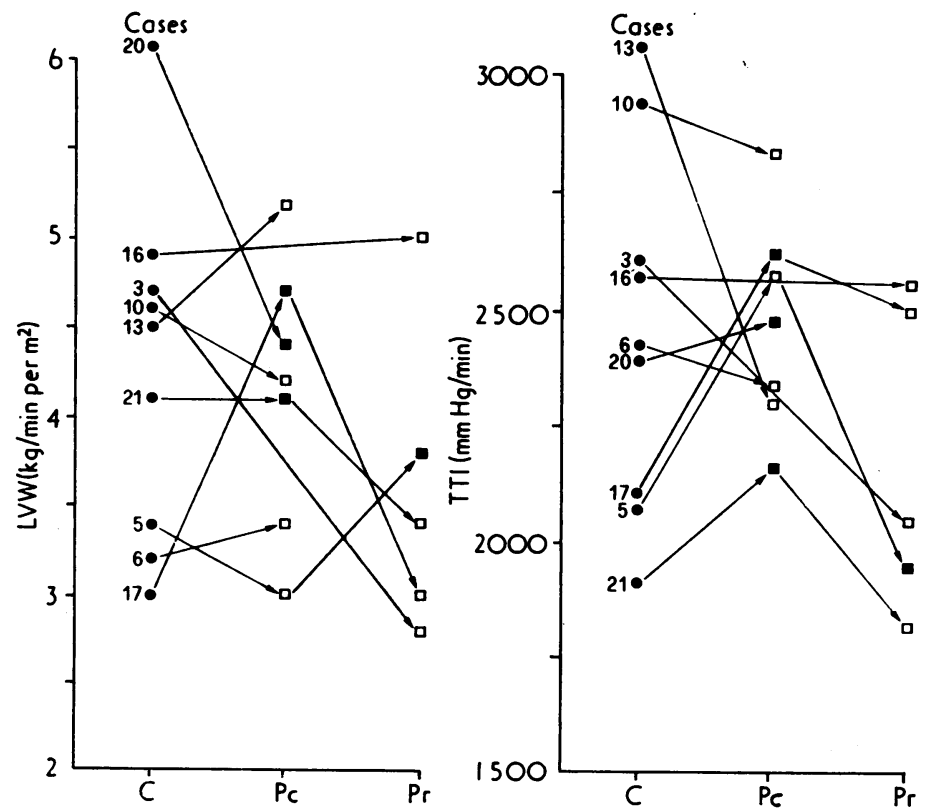

FIG. 2 Relation between changes of left ventricular work ( $L V W$ ) and tension-time index per minute (TTI) from the control state $(C)$, and antianginal effects of practolol (Pc) and propranolol $(\mathrm{Pr})$ in patients with type I angina pectoris. Values corresponding to full relief of angina are indicated by open squares. 


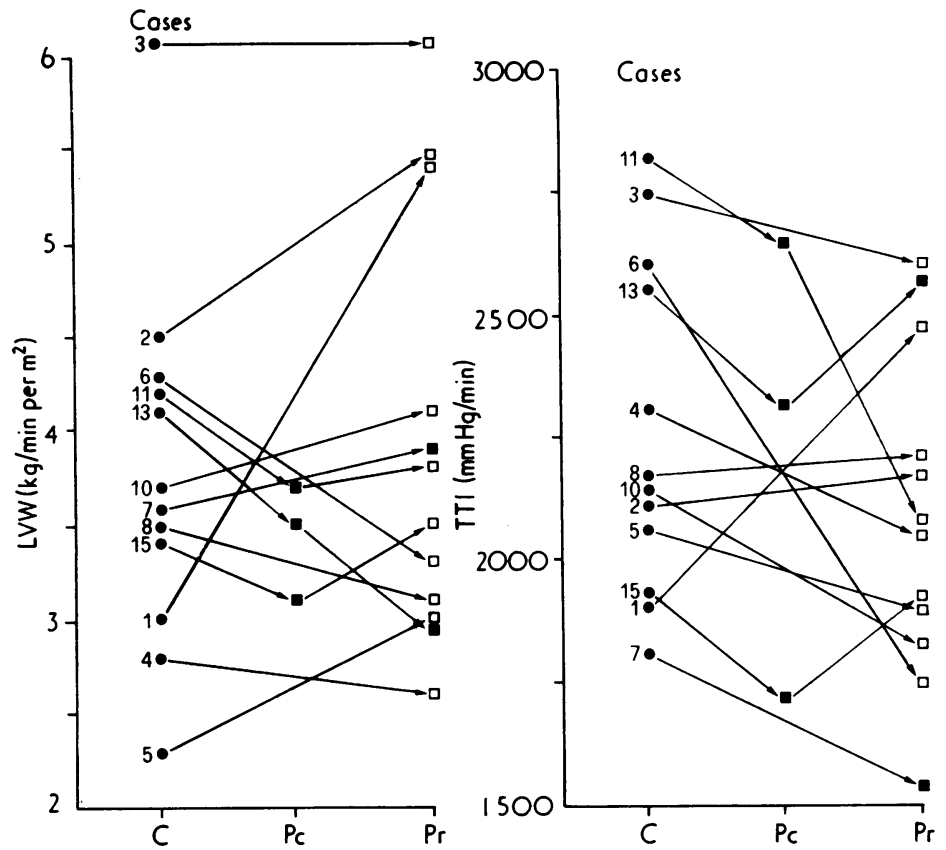

FIG. 3 Relation between changes of left ventricular work (LVW) and tension-time index per minute (TTI) from the control state (C), and antianginal effects of practolol $(P c)$ and propranolol $(\mathrm{Pr})$ in patients with type II angina pectoris. Values corresponding to full relief of angina are indicated by open squares.

The possible deleterious effect on the function of the heart is one of the major limitations in the use of beta-blocking agents. Concern about the risk of inducing heart failure can sometimes influence the management of patients with angina pectoris so as to prevent administration of these drugs in effective antianginal doses. It is felt that in the current study the number of patients and the doses of the beta-receptors antagonists were large enough to provide useful information on this topic.

In subjects of both groups (see under Methods) the circulatory function was evaluated in the untreated state and during treatment with beta blockers at the doses indicated in Tables 1 and 2. In Fig. 4 (type I angina) and Fig. 5 (type II angina) the haemodynamic values before therapy are compared with those detected in the same subjects after propranolol (blocked circles) or practolol (open circles). In type I angina propranolol significantly reduced the heart rate and cardiac index. The circulatory changes caused by practolol, though statistically not significant, indicate that the drug does not reduce, and possibly improves, the function of the heart. In type II angina the results were in some respects different. Propranolol again reduced the heart rate, but it significantly augmented the left ventricular $\mathrm{dP} / \mathrm{dt}$, mean rate of systolic ejection, and cardiac index. Changes induced by practolol were not significant.

\section{Discussion}

Previous favourable experience (Guazzi et al., 1971a) with beta blockers in spontaneous angina is confirmed in the present investigation: betaadrenergic antagonists fully abolished the symptoms in 80 per cent of the cases in type I and 73 per cent in type II angina.

Since placebo therapy itself can be successful in a high proportion of patients suffering from angina pectoris (Beecher, 1955), the assessment of treatment in this disease must be done with the utmost caution. In the current trial a placebo effect can be excluded because: (a) placebo administration in the run-in period was ineffective in each case; (b) in those patients who responded to the treatment substitution of placebo for the active drug caused prompt reappearance of the anginal symptoms; 

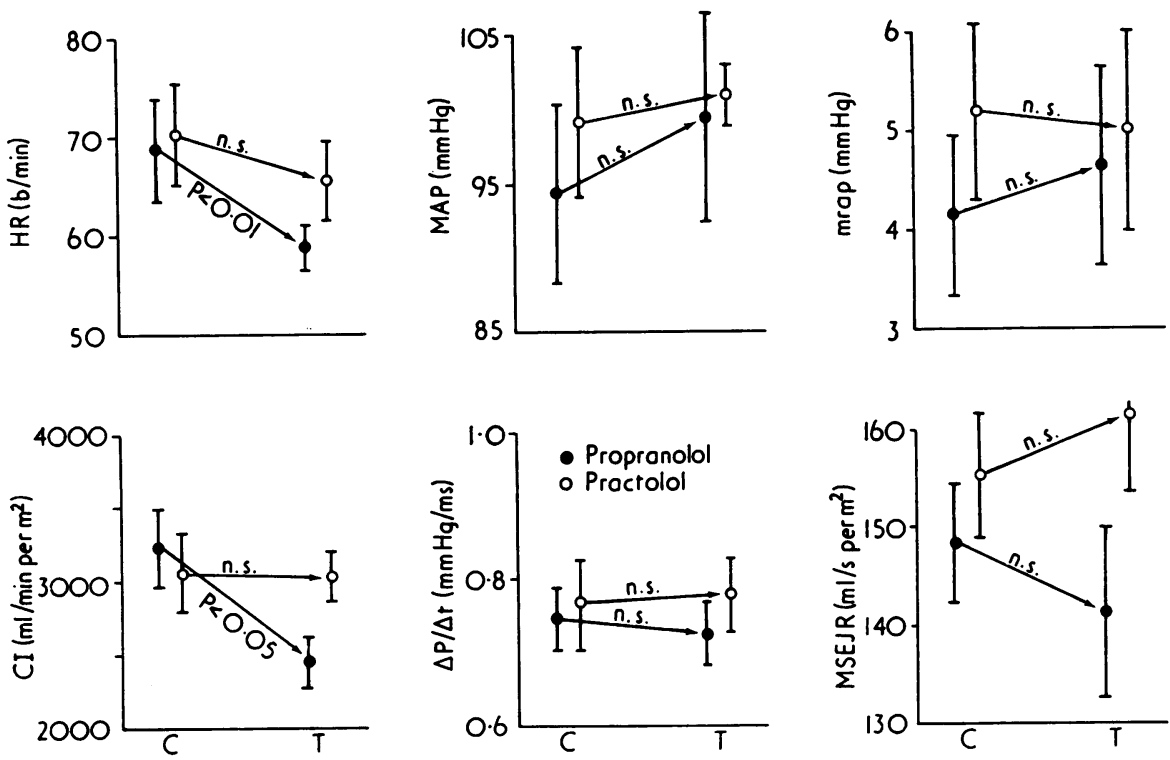

FIG. 4 Averages ( $\pm S E$ ) of haemodynamic functions in the control $(C)$ state and after treatment (T) with propranolol (blocked circles) and practolol (open circles) in patients suffering from type I angina pectoris. HR, heart rate; MAP, mean arterial pressure; $M R A P$, mean right atrial pressure; $C I$, cardiac index; $d P / d t$, left ventricular $d P / d t$; $M S E F R$, left ventricular mean rate of systolic ejection (index).
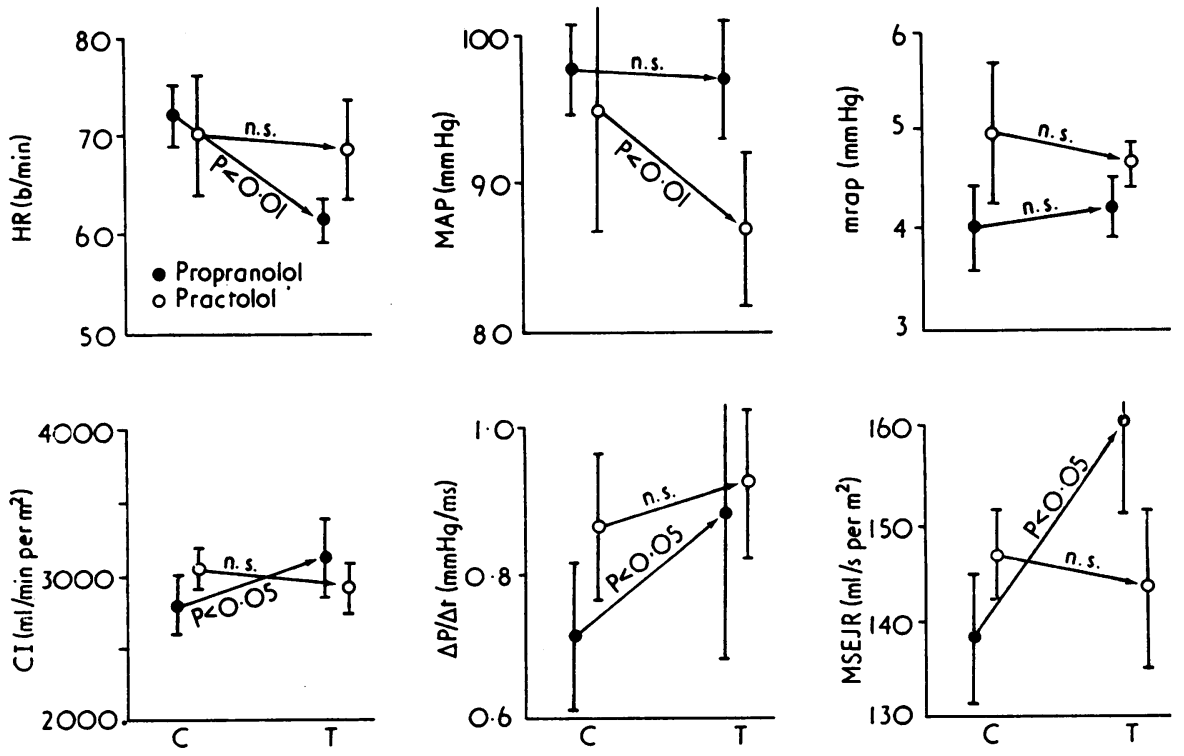

FIG. 5 Averages ( $\pm S E$ ) of haemodynamic values in the control $(C)$ state and after treatment $(T)$ with propranolol (blocked circles) and practolol (open circles) in patients suffering from type II angina pectoris. Abbreviations as in Fig. 4. 
(c) the improvement was obviously dose-dependent; $(d)$ in several cases the response was preferential to one of the two beta blockers; (d) after adequate doses the phasic electrocardiographic abnormalities disappeared in parallel with the relief of the subjective symptoms.

So far as we know no systematic study has been reported on the treatment of spontaneous angina pectoris by beta blockers. Unsatisfactory results have been reported in single cases (Whiting et al., 1970; MacAlpin, Kattus, and Alvaro, 1973; King et al., 1973; Bodenheimer et al., 1974; HernandezCasas, Dear, and Leachman, 1974). It is noteworthy that in the present investigation betablocking agents were not given in uniform, predetermined doses, but the dosage was increased until the optimal effect was achieved. This frequently occurred at relatively high doses of the drugs. We feel that patients with spontaneous angina might have been considered non-responders to beta blockers simply because they were treated with insufficient doses.

Three major sites of drug action may be involved in the improvement of angina: (a) the nervous pathways of transmission of anginal pain might be blocked, or the central awareness of pain altered; (b) the contractile effort and, consequently, the metabolic needs of the myocardium may be reduced; (c) the coronary blood supply or its regional distribution can be affected by relief of spasm in large vessels or by dilatation of arterioles and collaterals. The first of these hypotheses was advanced by Zeft, Patterson, and Orgain (1969) as an explanation of antianginal action of the beta blockers. On this basis questions were raised about the indication for propranolol in the treatment of this disorder, since the drug would remove the desirable warning signal of angina (Aronow, 1973). Findings in the present study disprove this assumption. Continuous electrocardiographic recordings, in fact, showed that beta blockers not only relieved pain but also abolished the electrocardiographic changes of ischaemia, even those changes that occurred in the absence of pain. This clearly demonstrates that these drugs prevent myocardial ischaemia and not simply the sensation of pain.

Restriction of the contractile effort and of the oxygen needs of the myocardium is the mechanism through which the effects of beta blockers in angina of effort are commonly explained. This interpretation, however, seems inadequate in spontaneous angina for the following reasons: (a) episodes of spontaneous angina occur during rest, when myocardial need for oxygen is low; (b) they are not preceded by changes in factors such as heart rate, blood pressure, cardiac output, or duration of right and left ventricular contraction which determine the myocardial oxygen consumption; (c) in no case did isoprenaline infusion, which necessarily increases the mechanical effort of the heart, precipitate angina.

A temporarily increased tonus of a large atherosclerotic coronary artery with a narrow lumen was suggested by Prinzmetal $\epsilon t$ al. (1959) as the cause of spontaneous angina with ST segment elevation. Subsequently several cases have been reported, some with normal coronary arteriograms, in which coronary spasm was detected during attacks of acute ischaemia (Ross and Gorlin, 1968; Dhurandhar et al., 1972; King et al., 1973; McAlpin et al., 1973; MacAlpin, 1973; Oliva, Potts, and Pluss, 1973; Linhart, 1974). Severe coronary spasm in association with anginal attacks has been found in some patients with classical angina pectoris (Gensini et al., 1962; Demany, Tambe, and Zimmerman, 1968). A possible role for coronary vasoconstriction has been suggested in this form of angina (MacAlpin, 1973). If changes in the vasomotor tone were really responsible for spontaneous angina, one could postulate a direct or mediated influence of the beta-blocking agents on the coronary vasomotor system.

No factor could be isolated by clinical and haemodynamic criteria to account for a favourable response to beta blockers in one patient as opposed to no benefit in another, or for a favourable effect of one beta blocker as opposed to no benefit from the other. Changes of the baseline left ventricular load were unrelated to the improvement of the anginal symptoms. Angiographic studies of the coronary vessels were not carried out systematically; data available, however, do not indicate a relation between benefit from beta blockade and presence or severity of coronary lesions. Therefore these analyses did not help to shed light on the mechanisms of action of beta blockers in spontaneous angina pectoris.

Doses required for complete abolition of the anginal attacks were generally high and possibly in excess of those necessary for cardiac beta blockade in man. It is reasonable to wonder whether beta blockade of the heart and anginal blockade are two separate phenomena, each induced by different doses of beta blocker. Such dissociation could be established through a precise definition and comparison of the amounts which induce full cardiac beta blockade and of those which relieve angina. Though the doses which inhibited the heart rate response to isoprenaline were greatly and significantly lower than those effective on angina, the question cannot be considered definitely answered, since in terms of antagonism of iso- 
prenaline the concept of complete beta-receptor blockade is not meaningful. None the less, the isoprenaline tests have provided evidence that equivalent amounts of propranolol and practolol can have comparable influences on the isoprenalineinduced tachycardia and greatly different effects on the anginal symptoms. In other words, the degree of beta-receptor antagonism does not correlate with the improvement in angina, which supports the possibility that cardiac beta blockade and blockade of spontaneous angina are not directly related to each other.

In conclusion, our findings exclude a mere local anaesthetic cell membrane effect; show that beta blockers really prevent myocardial ischaemia; indicate that prevention of ischaemia of spontaneous angina is not attributable, or at least entirely attributable, to a decrease of the mechanical effort of the heart and its oxygen demand; suggest the existence of an additional still undefined effect, possibly dissociated from the beta blockade of the heart as well as from the membrane activity of these drugs.

Congestive heart failure, the most serious untoward effect of the beta-receptor antagonists, follows from the negative inotropic action of these agents (Epstein et al., 1965; Sonnenblick et al., 1965; Bloomfield and Sowton, 1967), but has actually been an uncommon clinical occurrence (Wolfson et al., 1966; Gillam and Prichard, 1966; Conway, Seymour, and Gelson, 1968). Amsterdam, Gorlin, and Wolfson (1969) have reported that propranolol was tolerated in a large number of patients suffering from angina with evidence of congestive heart failure before treatment. In the present study practolol did not significantly alter the circulatory function of the patients in both groups. As compared to propranolol, in type I angina it induced a minor degree of bradycardia and less depressive effect on the cardiac inotropic state. It is also noteworthy that practolol cleared the symptoms and restored the circulatory function in two patients in this group who developed cardiac insufficiency following propranolol. These findings are in good agreement with the haemodynamic reports of other authors (Sowton et al., 1968; Jewitt, Burgess, and Shillingford, 1970; Leon et al., 1972). The circulatory effects of propranolol were, under some aspects, opposite in type II as compared to type I angina. In the former group of patients changes in cardiac index, $\mathrm{dP} / \mathrm{dt}$, and mean systolic ejection rate confirm our previous observations (Guazzi et al., 1971a) and provide statistical evidence of the favourable effects of propranolol on the left ventricular function of patients suffering from type II angina. The inter- pretation of these findings, which contrast with those of many authors (Epstein et al., 1965; Hamer and Sowton, 1965; Sonnenblick et al., 1965), is not immediately apparent. Since propranolol proved to be effective in this type of angina, it might be postulated that the improvement of cardiac function after propranolol influenced in some way the relief of angina, or, what seems more convincing, that cardiac function improved because the coronary circulation was ameliorated and angina abolished.

From a practical point of view the study suggests that: in spontaneous angina beta blockers are worthy of trial; the dosage must be individualized and, in the absence of untoward side effects, increased until the optimal response is achieved; the occurrence of heart failure is uncommon even at high doses of beta-blocking agents; one drug may produce beneficial effects where another has failed; the use of propranolol is preferable in cases of angina showing ST segment elevation.

\section{References}

Amsterdam, E. A., Gorlin, R., and Wolfson, S. (1969). Evaluation of long-term use of propranolol in angina pectoris. Fournal of the American Medical Association, 210, 103.

Aronow, W. S. (1973). Management of stable angina. New England fournal of Medicine, 289, 516.

Beecher, H. K. (1955). Appraisal of drugs intended to alter subjective responses, symptoms. Fournal of the American Medical Association, 158, 399.

Bloomfield, D. A., and Sowton, E. (1967). Rate-independent effects of propranolol: the differentiation between chronotropic, inotropic, and peripheral vascular responses. Circulation Research, Suppl. III.

Bodenheimer, M., Lipski, J., Donoso, E., and Dack, S. (1974). Prinzmetal's variant angina: a clinical and electrocardiographic study. American Heart fournal, 87, 304.

Conway, N., Seymour, J., and Gelson, A. (1968). Cardiac failure in patients with valvar heart disease after use of propranolol to control atrial fibrillation. British Medical fournal, 2, 213.

Demany, M. A., Tambe, A., and Zimmerman, H. A. (1968). Coronary arterial spasm. Diseases of the Chest, 53, 714.

Dhurandhar, R. W., Watt, D. L., Silver, M. D., Trimble, A. S., and Adelman, A. G. (1972). Prinzmetal's variant form of angina with angiographic evidence of coronary arterial spasm. American fournal of Cardiology, 30, 902.

Epstein, S. E., Robinson, B. F., Kahler, R. L., and Braunwald, E. (1965). Effects of beta-adrenergic blockade on the cardiac response to maximal and submaximal exercise in man. Fournal of Clinical Investigation, 44, 1745.

Fitzgerald, J. D. (1969). Perspectives in adrenergic betareceptor blockade. Clinical Pharmacology and Therapeutics, 10, 292.

Gensini, G. G., Di Giorgi, S., Murad-Netto, S., and Black, A. (1962). Arteriographic demonstration of coronary artery spasm and its release after the use of a vasodilator in a case of angina pectoris and in the experimental animal. Angiology, 13, 550.

Gillam, P. M. S., and Prichard, B. N. C. (1966). Propranolol 
in the therapy of angina pectoris. American fournal of Cardiology, 18, 366.

Gorlin, R. (1965). Pathophysiology of cardiac pain. Circulation, 32, 138.

Guazzi, M., Magrini, F., Fiorentini, C., and Polese, A. (1971a). Clinical, electrocardiographic, and haemodynamic effects of long-term use of propranolol in Prinzmetal's variant angina pectoris. British Heart fournal, 33, 889.

Guazzi, M., Polese, A., Fiorentini, C., Magrini, F., and Bartorelli, C. (1971b). Left ventricular performance and related haemodynamic changes in Prinzmetal's variant angina pectoris. British Heart fournal, 33, 84.

Guazzi, M., Polese, A., Fiorentini, C., Magrini, F., Olivari, M. T., and Bartorelli, C. (1975). Left and right heart haemodynamics during spontaneous angina pectoris. Comparison between angina with ST segment depression and angina with ST segment elevation. British Heart Fournal, 37, 401.

Hamer, J., and Sowton, E. (1965). Cardiac output after betaadrenergic blockade in ischaemic heart disease. British Heart fournal, 27, 892.

Hernandez-Casas, G., Dear, W., and Leachman, R. D. (1974). Prinzmetal's variant angina pectoris with normal coronary arteriograms: effect of long-term reserpine treatment. Cardiovascular Diseases. Bulletin of the Texas Heart Institute, 1, 194.

Jewitt, D. E., Burgess, P. A., and Shillingford, J. P. (1970). The circulatory effects of Practolol (ICI 50172) in patients with acute myocardial infarction. Cardiovascular Research, 4, 188.

King, M. J., Zir, L. M., Kaltman, A. J., and Fox, A. C. (1973) Variant angina associated with angiographically demonstrated coronary artery spasm and REM sleep. American Fournal of the Medical Science, 265, 419.

Leon, D. F., Thompson, M. E., Shaver, J. A., and McDonald, R. H. (1972). Hemodynamic effects of practolol at rest and during exercise. Circulation, 45, 46.

Linhart, J. W. (1974). Prinzmetal variant of angina pectoris fournal of the American Medical Association, 228, 342.
MacAlpin, R. (1973). Coronary spasm as a cause of angina. New England fournal of Medicine, 288, 788.

McAlpin, R. N., Kattus, A. A., and Alvaro, A. B. (1973). Angina pectoris at rest with preservation of exercise capacity. Prinzmetal's variant angina. Circulation, 47, 946.

Oliva, P. B., Potts, D. E., and Pluss, R. G. (1973). Coronary arterial spasm in Prinzmetal angina. Documentation by coronary arteriography. New England fournal of Medicine, 288, 745.

Prinzmetal, M., Kennamer, R., Merliss, R., Wada, T., and Bor, N. (1959). Angina pectoris. I. A variant form of angina pectoris. American fournal of Medicine, 27, 375.

Ross, R. S., and Gorlin, R. (1968). Coronary arteriography. Circulation, 38 III-67.

Sonnenblick, E. H., Braunwald, E., Williams, J. F., and Glick, G. (1965). Effects of exercise on myocardial forcevelocity relations in intact unanesthetized man: relative roles of changes in heart rate, sympathetic activity and ventricular dimensions. Fournal of Clinical Investigation, 44, 2051.

Sowton, E., Balcon, R., Cross, D., and Frick, H. (1968). Haemodynamic effects of ICI 50172 in patients with ischaemic heart disease. British Medical fournal, 1, 215.

Weissler, A. M., Harris, W. S., and Schoenfeld, C. D. (1968). Systolic time intervals in heart failure in man. Circulation, 37, 149.

Whiting, R. B., Klein, M. D., Vander Veer, J., and Lown, B. (1970). Variant angina pectoris. New England fournal of Medicine, 282, 709.

Wolfson, S., Heinle, R. A., Herman, M. V., Kemp, H. G., Sullivan, J. M., and Gorlin, R. (1966). Propranolol and angina pectoris. American fournal of Cardiology, 18, 345.

Zeft, H. J., Patterson, S., and Orgain, E. S. (1969). The effect of propranolol in the long-term treatment of angina pectoris. Archives of Internal Medicine, 124, 578.

Requests for reprints to Dr. Maurizio Guazzi, Istituto Ricerche Cardiovascolari, Via Francesco Sforza, 35, 20122 Milan, Italy. 